\title{
Developing a location research methodology
}

Received (in revised form): 18th January, 2005

\section{David S. Rogers}

is President of DSR Marketing Systems, based in the Chicago area of the USA. Founded in 1979, DSR provides consultancy to retail clients in the UK, Europe, the Middle East, North America and Australia, on consumer spending estimates, site evaluation, store location analysis and consumer research.

\begin{abstract}
This paper seeks to encourage retailers, and other parties involved in retail development such as fast food chains, financial institutions and shopping centre developers, to engage in thoughtful long-term planning as to how new locations are selected and developed. This is a difficult objective to achieve in an era of 'canned' data solutions and pressurised decision making. It is, however, the hallmark of some of the more successful retailers in the world, such as Tesco.
\end{abstract}

\section{INTRODUCTION: THE NEED}

Why should retailers or the development community invest significant time and money in establishing reliable location research methods? There are five key reasons:

- to avoid costly locational mistakes, such as Best Buy's acquisition of the Musicland Stores Group or Bentall's ill-fated expansion to Bristol.

Frequently, the cost in lost time and management focus is even more expensive than that of money;

- to survive the economic downturns and competitive changes that inevitably occur over the long term. Irrespective of the short-term reward of not making a mistake, durable store locations are necessary;

- to avoid being caught by

David Rogers DSR Marketing Systems, Inc., 108 Wilmot Road, Deerfield, IL 60015, USA.

Tel: +1 847940 8200; Fax: +1 8479408237 ; e-mail:

dsrms@sbcglobal.net longer-term trends affecting the geography of demand. Decentralisation is a macro trend in most societies, despite government intervention as in the UK, and has increased the uncertainty involved in selecting retail locations. No longer is it possible to work from simple lists of prime high streets or regional shopping centres;

- to address the increased fragmentation of consumer markets, a major trend in most advanced societies, whether on the basis of incomes, age or ethnic background. This means that retailers can no longer simply count the total population within a local trading area but increasingly need to assess accurately whether there are enough people with the right demographic characteristics;

- to maintain and improve the performance of the existing estate. Even if a retailer is not opening new stores, location research methods are essential to analyse and improve the performances of existing retail facilities. These analyses underpin decisions on which stores to close, which to refurbish or remodel, and how to re-brand or re-position stores and shopping centres for a more profitable future. 


\section{ACHIEVING THE OBJECTIVE}

Having established the need for reliable location research methods, how does a retailer go about developing an appropriate methodology? An effective location research method is much more than just databases and techniques.

Specifically, it requires a sound research design and plan at the outset. This important point is often forgotten by data firms and consultancies which are frequently over eager to promote their specific databases or techniques.

Retail development, whether of individual stores or entire shopping centres, is obviously a complex decision-making process and much more than just a way of forecasting sales. Rather, it represents the entire manner in which a management makes decisions about investing in retail facilities. There is, therefore, a prime need to organise how location research techniques will be used within the business. The author has worked with too many retailers and restaurant operators who spent large sums of money on data without a plan... and ended up with nothing but useless demographic and lifestyle cluster reports: useless because they were data that never became information.

When organising for the development of location research systems, there are three important considerations which should be recognised and given thought. These are the:

- expansion planning process;

- relevant sources of business;

- alternative forecasting methods.

\section{THE EXPANSION PLANNING PROCESS}

There are five important stages in the expansion planning process: market selection; locational strategies, site screening; sales forecasting; and financial analysis.

1. Market selection: for example, Burberry may need to decide on the relative investment priorities of China and Japan. If the latter is selected, is the focus purely on greater Tokyo or is Osaka also a candidate for store development?

2. Locational strategies for selected markets. That is, how many Burberry outlets can the greater Tokyo market support, and where are the best locations within Tokyo?

3. For the preferred locations within a specific market, the next important stage is initial site screening. That is, the evaluation of one or more sites within the preferred location. The prime purpose of this evaluation is to establish the priorities for attention by the property or real estate staff. The importance of effective site-screening methods is increasing as sales forecasting techniques have become more costly, sophisticated and time consuming. This importance is also being reinforced by the increasing focus of most retailers on expense reduction, value and price. If they are to offer a value proposition, retailers cannot afford unlimited head office costs. A good example is Tesco in Great Britain. During Tesco's major domestic growth phase, each year, over 1,000 sites throughout the UK were being brought to the attention of Tesco's property department. Of these, about half, ie 500, were referred to the site research department. About 250 were then screened out, enabling the department to focus on the 250 which most merited attention. This process enables the work to be done by a smaller staff than would be required for 500 in-depth evaluations.

4. Following site screening and an initial evaluation, the fourth stage is the in-depth site appraisal and the 
development of a final sales forecast or turnover estimate. This activity should be reserved for those sites which the retailer is serious about developing.

5. A fifth and final stage is the conduct of a detailed financial analysis of the opportunity based on the projected sales and the costs of development and operation.

\section{RELEVANT BUSINESS SOURCES}

After thinking through the expansion planning process, the second important consideration relates to the business sources served by the retailer, restauranteur or shopping centre (see Table 1). These have a major impact on the way in which a location research method is designed and developed, and the databases and techniques which are relevant. For example, in the 1970s, petrol (gas) stations typically only served neighbourhood locations and the gravity model worked well in analysing what was essentially a home-based business source. This scenario is no longer applicable because of the development of highway-oriented petrol pumpers where the majority of sales are drawn from passing traffic and/or adjoining land uses, such as hypermarkets, workplaces or shopping centres. Accordingly, a residential-oriented gravity modelling method must now be supplemented by additional techniques, including penetration rates for passing traffic. The relative importance of business sources can also change over time as Oxford Street retailers have found to their cost with regards to tourist spending.

\section{THE ALTERNATIVE METHODS}

The third key consideration is the decision as to which method, or methods, should be developed and employed. Seven commonly-used
Table 1: Alternative business sources

Home-based

Work-based

Adjoining land uses

Drive-by/highway-oriented

Tourists

Table 2: Alternative methods

Geodemographic systems

Ratio method

Market support method

Analogue method

Multivariate statistical models

Gravity/spatial interaction models

Factor and cluster analysis

methods and models are listed in Table 2 . These can all contribute to the various stages in the expansion planning process but with varying degrees of relevance. ${ }^{1,2}$ For example, the highly-promoted geodemographic methods, such as ACORN, MOSAIC and PRIZM are helpful in market selection and in the identification of preferred locations within selected markets.

The simple ratio and market support methods are frequently used at UK planning inquiries to prove, or disprove, the need for additional retail development. They are, however, also helpful in market and site screening and, for retailers with few prototype stores (see below), they may have to be the final sales forecasting tool.

The analogue method and multivariate statistical models, such as stepwise multiple regression analysis, are best applied to develop sales forecasts for individual sites while gravity models are the most effective approach for arriving at the optimum locational strategies for store networks. The latter is a common concern of banks, fast food chains, petrol retailers and service providers.

Having noted these important points, it is now appropriate to focus on the main sales forecasting methods and 
review the management objectives they can fulfil, their relevance to different types of retail operation and their database requirements.

\section{MANAGEMENT OBJECTIVES}

The major considerations in selecting the most appropriate sales forecasting technique(s) begin with the management criteria and objectives listed in Table 3.

First, and most important, what resources will be made available to develop a location research method, support and update it over time, and apply it day in, day out? There is obviously no point whatsoever in developing a people-intensive sophisticated method if the appropriate staff will not be available to execute it. In this circumstance, a simpler method that can be applied routinely and quickly would be much more effective.

Next, what is the investment risk associated with a new store opening? There is obviously much less risk associated with the opening of a Tesco Express convenience store than with a Tesco Extra hypermarket. Accordingly, different financial and time investments and techniques are appropriate to the two store formats. This consideration can also change over time for essentially the same store format. For example, the highly successful Walgreen's drug store chain in the USA formerly employed a fieldwork intensive gravity model but during the 1990s reverted to a sophisticated version of the analogue method as its freestanding prototype store became more standardised and predictable.

Another consideration is the pace of change affecting stores. The less stable the future store prototype, the less the retailer should invest in a modelling method that presents a static picture,
Table 3: Management crieria

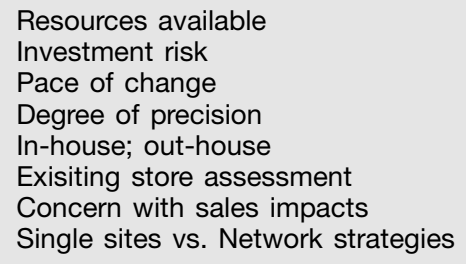

which might cost six figures to develop and must be totally redeveloped every three years.

What degree of precision is required from a forecasting method? That is, how sure does management have to be about the sales expectations for a new store? Is it sufficient to know the approximate sales range, such as between $\$ 600,000$ and $\$ 700,000$ per year, or is an exact sales forecast required? That is, is the difference between $\$ 600,000$ and $\$ 700,000$ important in terms of the return on investment?

Does management prefer the confidentiality of an in-house research unit (also a fixed overhead expense), the independent view of an external consultant (who is also a variable expense), or something of both?

Does management also require insights into existing store performances and where and how they can be improved? That is, a store assessment objective. If so, this requirement may mean analysing a different database from that for a straightforward sales forecasting requirement.

Finally, is the store development focus going to be on single sites one at a time? Or is there concern with the sales impacts of a new store on its existing sister stores, and a need for the development of location or network strategies for existing or new markets? This latter objective is typically the concern of banks, convenience retailers, petrol (gas) stations and fast food chains such as McDonald's and Subway. 


\section{CHARACTERISTICS OF THE RETAIL OPERATION}

This point concerns the importance to the appropriateness of any sales forecasting technique - of the type of retail operation, specifically its trading performances and target customers. For example, pub and restaurant chains and clothing retailers - which are often highly segmented in their appeals to different demographic groups - typically employ the analogue and multivariate statistical methods. They cannot use gravity models which are segmentation blind. This, however, is also becoming increasingly true of the American supermarket industry which has traditionally chosen the gravity model as its technique of choice. For example, both US businesses Save-A-Lot (discount stores) and Whole Foods (natural/organic foods) now employ multivariate methods - rather than gravity models - because of their segmented appeals at two opposite ends of the demographic spectrum.

\section{DATABASE REQUIREMENTS}

Thirdly, and finally, the number of prototype stores operated by the retailer is a crucial consideration governing the selection of sales forecasting techniques. Prototype stores are those existing stores which are substantially similar to those stores which will be developed in the future on the basis of the sales forecasting system. In the real world, this requires the frequent updating of the relevant database since prototypes change over time.

The performance of prototype stores (ie analogues) provides the foundation of any reliable method of retail sales forecasting. Accordingly, their number imposes an important constraint on the methods that can be used. For example, if a retailer, such as the UK's Marks and
Spencer, is developing an entirely new store concept - such as its first Simply Food convenience store or its ill-fated Lifestore - it is limited to using simple procedures, such as the ratio or market support methods, and/or employing carefully-determined adjustments of any available relevant store performance data (including that for competitors). If, however, the retailer has 30 or more existing prototype stores, then more scientific modelling methods can be considered, such as multiple regression analysis.

Whichever technique (or set of techniques) is selected, it must be stressed that there are no black boxes, whatever some consultants and data firms may claim. Nor is any one method the best. There are horses for courses.

There is also a constant need for vigilance against the dumbing down and cosmetic comfort that can be associated with — or engendered by - geographical information systems (GIS). Despite attractive coloured maps and apparently seamless data integration, retailers need to constantly question and probe the underlying data and methodologies within GIS. For example, how — exactly — have the population estimates for local areas been arrived at? Do they reflect the geographical distribution of housing permits since the last census, and/or the distribution of household delivery addresses by postal carrier routes? Or were the findings of the last census merely pumped up by a generalised growth factor produced by a government agency for a large area?

Similarly, are the specific cluster types in a canned lifestyle system truly relevant to the retailer's customers or non-customers? And do the penetration indices by cluster type merely reflect the retailer's past locational decision making? 


\section{THE PREFERENCE FOR MODELS}

When selecting location research methods, it is desirable - whenever possible - to reduce subjectivity and develop more objective modelling methods. There are, however, a number of important issues concerning sales forecast models which must be borne in mind. Seven of these are reviewed below.

First, forecasting models reduce the degree of subjectivity but do not remove it. By definition, models are simplifications of reality and are rarely, if ever, comprehensive with respect to all the factors influencing the level of sales at a retail site. Many models do not pretend to be anything other than partial indicators, for example, those based purely on demographic data. This is not a problem as long as it is communicated and fully understood.

A second issue is that the capabilities of individual models have frequently been oversold by data firms and consultants and failed to live up to their promises. The head of site research at one of the major American home improvement retailers has said that he will never again buy any data or system from a firm with a sales force.

Thirdly, by their nature, sales forecasting models can be complex and difficult to explain. Because of their wide-ranging responsibilities, many senior retail executives do not have the time to comprehend models fully and, as a result, become impatient with, or confused by, them.

Fourthly, sales forecasting models are frequently developed by academics and data firms who do not adequately understand the practical context of their application. As a result, the models have high levels of reliability in theory, but work poorly in practice. A mid-size American restaurant chain makes an excellent example. The firm in question decided to become more sophisticated about forecasting the sales of new restaurants and retained an academic who developed a multiple regression model for this purpose. It was the right method but developed in the wrong manner. All the chain's existing units were entered into the model development database including old high street restaurants with no parking together with new suburban branches which had high sales and excellent parking facilities. The resulting multivariate analysis produced a forecasting model in which the amount of parking was found to be the most important variable in determining sales. Therefore, the restaurant chain built new units with ever larger parking areas. Unfortunately, sales did not go up but expenses did. The model consistently over-forecast because irrelevant non-prototype units with no parking had been incorrectly included in the forecasting database.

Fifthly, the example presented above nicely makes the point that models are highly dependent on the quality of data and judgments employed in their development and application. Inappropriate variables - or too many variables in conflict with the assumptions of the technique - are employed too often. A major UK high street retailer provides another instructive example. The key variable in its multivariate sales forecasting model was the level of rent to be paid at a prospective site. The inclusion of this variable in the model was because the level of sales was really determined by the amount of passing pedestrian traffic at their existing stores which, in turn, was reflected in the amount of rent paid. This problem is termed collinearity.

Sixthly, many models, and particularly the multivariate techniques, have fixed structures. This can be an important issue in a dynamic field such as retailing since 


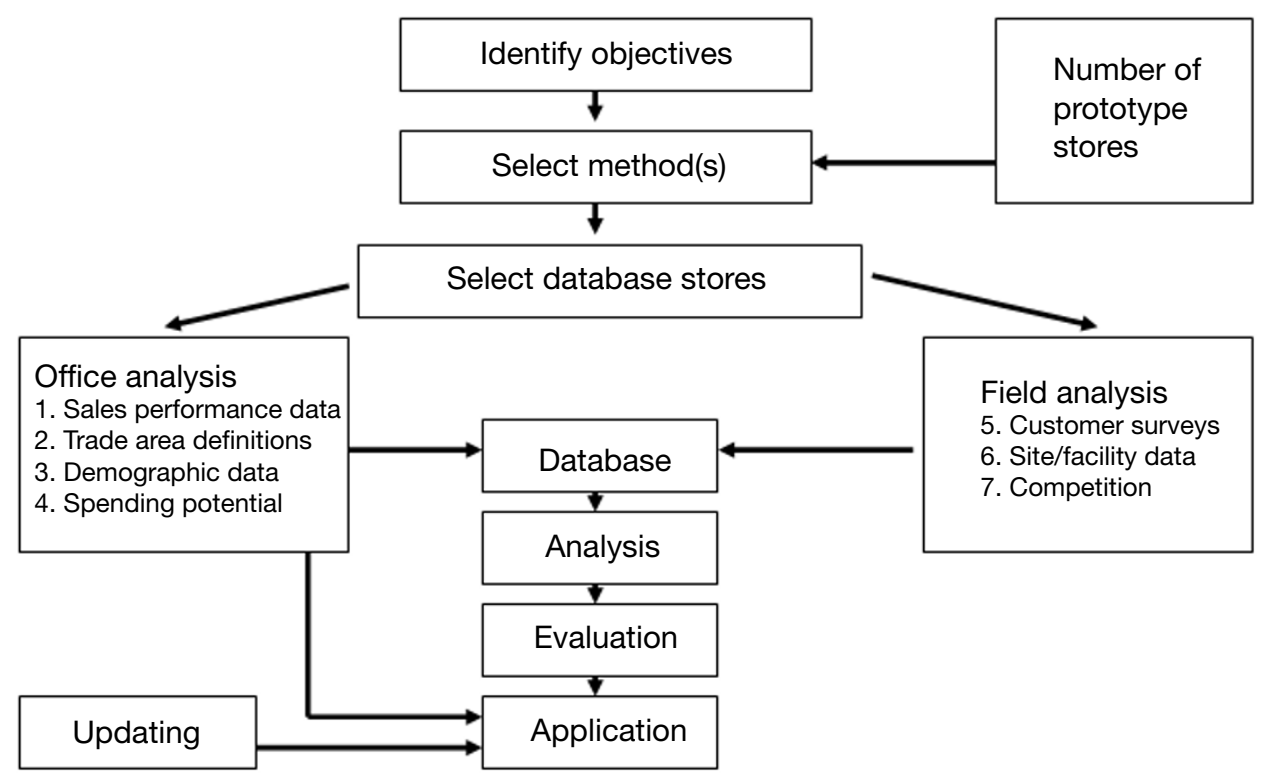

Figure 1 System development overview

the predictive quality of the models declines rapidly as time goes by. The obvious answer is that regular updating must take place - but it has to be budgeted for.

Finally, models rarely include crucial site factors, such as poor visibility at a car park exit or unfavourable land-use adjacencies. Many site factors are difficult to quantify but can have a dramatic negative effect on store sales. A key reason why they are rarely included in sales forecasting models is that retailers frequently avoid site-specific problems even when they are relatively unsophisticated in terms of the location research methods employed (the problems with sales usually occur further away from the store). Therefore, there is not the range of experience within the model development database for site factors to appear as significant variables in models. Furthermore, any disasters produced by unfavourable site characteristics are usually quickly closed and, therefore, are not subsequently available for study. Accordingly, the absence of site factors in most models requires that a separate site evaluation checklist or procedure be developed to supplement the sales forecasting system.

To a greater or lesser degree, therefore, models are only partial indicators. Modelling does not make retail location analysis an objective science. Rather, it merely reduces the degree of subjectivity. A lot of common sense, practical experience and field analysis are still essential in selecting sites for profitable retail developments.

Once a retailer is ready to develop a location research method, there are a series of key steps in developing a system which are identified in the accompanying Figure 1. To be effective, this process of development requires careful homework, the full involvement of the retailer (whether or not an outside consultancy is involved) and must be accomplished thoroughly. Also it is not a one-time effort. The resulting system must be constantly re-evaluated and updated as time goes by. This should be considered when establishing the initial budget. 
Table 4: Factors to consider

Facility characteristics

Site characteristics

Development and operating costs

Road/access patterns

Competition

Demographics/spending potential

The local economic base

There is no point in spending a lot on a sophisticated system that, for financial reasons, cannot be updated regularly. A wiser approach would be to develop a less complex and less expensive system that can be updated for changing conditions over time.

\section{CONCLUDING COMMENTS}

Finally, whichever location research method - or series of methods - is selected by a retailer, restauranteur or shopping centre developer, all the relevant factors that can produce success or failure must be considered when evaluating prospective sites. ${ }^{3}$ These are listed in Table 4 and include:

- facility characteristics: for example, store sizes and product ranges, the tenant mix of shopping centres and the presence or absence of a car wash and convenience store at a new fuel facility;

- site characteristics: that is, parcel sizes and shapes, visibility, ingress-egress characteristics, circulation and parking arrangements, the size and type of shopping centre, and the presence or absence of preferred retail co-tenants;

- development and operating costs;
- street and highway access patterns: do they 'lead' shoppers to the site or steer them away? Are there travel barriers, such as rivers and railway lines, which truncate the likely catchment area to be served;

- competition: their locations, sizes, sales, parking facilities, facility conditions, quality of operations and price positioning;

- local catchment area demography: that is, their growth (or decline) trends, socioeconomic characteristics, and expenditure patterns and preferences;

- the economic base of local market areas: that is, are they growing or declining? Who are the major employers? What are the income levels and employment prospects?

In the author's 30-year experience of carrying out site research, it is the quality and thoroughness of the field analysis that determines the accuracy of a site evaluation and sales forecast as much as which particular sales forecasting method is employed. Despite the trends to reduce head office costs, systematisation and travel minimisation, successful retail site selection cannot be achieved solely by clicking a mouse in a nice comfortable office.

\section{References}

1 Davies, R. L. and Rogers, D. S. (1984) 'Store location and store assessment research', John Wiley and Sons Ltd, London, UK.

2 Birkin, M. (2002) 'Retail geography and intelligent network planning', John Wiley and Sons Ltd.

3 Snow, W. and Scott, K. (1984) 'Site appraisals' in Davies, R. L. and Rogers, D. S. (1984) op. cit. 